\title{
Front Matter: Volume 10153
}

, "Front Matter: Volume 10153," Proc. SPIE 10153, Advanced Laser Manufacturing Technology, 101531B (8 November 2016); doi:

$10.1117 / 12.2264630$

SDIE Event: International Symposium on Optoelectronic Technology and SPIE. Application 2016, 2016, Beijing, China 


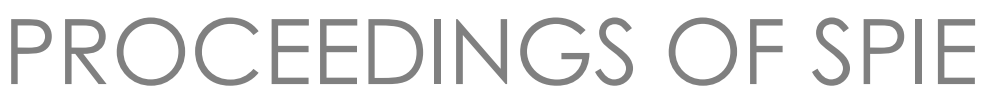

\section{Advanced Laser Manufacturing Technology}

\section{Bingheng Lu \\ Huaming Wang \\ Editors}

\section{9-11 May, 2016 \\ Beijing, China}

\section{Organized by}

Chinese Society for Optical Engineering (CSOE) (China)

Photoelectronic Technology Committee, Chinese Society of Astronautics (China)

Photo-electronic Industrialization Committee, CHIA (China)

Department of Cooperation and Coordination for Industry, Academe and Research, CHIA

(China)

Sponsored by

Chinese Society for Optical Engineering (CSOE) (China)

China High-tech Industrialization Association (CHIA) (China)

Technical Co-sponsor and Publisher

SPIE 
The papers in this volume were part of the technical conference cited on the cover and title page. Papers were selected and subject to review by the editors and conference program committee. Some conference presentations may not be available for publication. Additional papers and presentation recordings may be available online in the SPIE Digital Library at SPIEDigitallibrary.org.

The papers reflect the work and thoughts of the authors and are published herein as submitted. The publisher is not responsible for the validity of the information or for any outcomes resulting from reliance thereon.

Please use the following format to cite material from these proceedings:

Author(s), "Title of Paper," in Advanced Laser Manufacturing Technology, edited by Bingheng Lu, Huaming Wang, Proceedings of SPIE Vol. 10153 (SPIE, Bellingham, WA, 2016) Seven-digit Article CID Number.

ISSN: 0277-786X

ISSN: 1996-756X (electronic)

ISBN: 9781510607644

ISBN: 9781510607651 (electronic)

Published by

SPIE

P.O. Box 10, Bellingham, Washington 98227-0010 USA

Telephone +1 3606763290 (Pacific Time) · Fax +1 3606471445

SPIE.org

Copyright (C) 2016, Society of Photo-Optical Instrumentation Engineers.

Copying of material in this book for internal or personal use, or for the internal or personal use of specific clients, beyond the fair use provisions granted by the U.S. Copyright Law is authorized by SPIE subject to payment of copying fees. The Transactional Reporting Service base fee for this volume is $\$ 18.00$ per article (or portion thereof), which should be paid directly to the Copyright Clearance Center (CCC), 222 Rosewood Drive, Danvers, MA 01923. Payment may also be made electronically through CCC Online at copyright.com. Other copying for republication, resale, advertising or promotion, or any form of systematic or multiple reproduction of any material in this book is prohibited except with permission in writing from the publisher. The CCC fee code is 0277-786X/16/\$18.00.

Printed in China.

Publication of record for individual papers is online in the SPIE Digital Library.

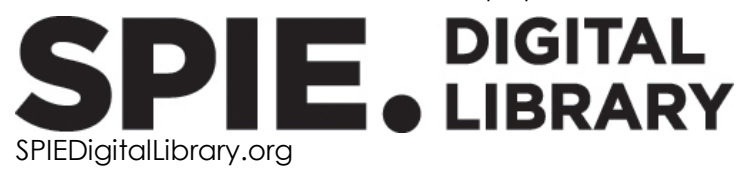

Paper Numbering: Proceedings of SPIE follow an e-First publication model. A unique citation identifier (CID) number is assigned to each article at the time of publication. Utilization of CIDs allows articles to be fully citable as soon as they are published online, and connects the same identifier to all online and print versions of the publication. SPIE uses a seven-digit CID article numbering system structured as follows:

- The first five digits correspond to the SPIE volume number.

- The last two digits indicate publication order within the volume using a Base 36 numbering system employing both numerals and letters. These two-number sets start with 00, 01, 02, 03, 04, 05, 06, 07, 08, 09, OA, OB ... 0Z, followed by 10-1Z, 20-2Z, etc. The CID Number appears on each page of the manuscript. 


\title{
Contents
}

\author{
vii Authors \\ ix Conference Committees \\ xi Introduction
}

\section{ADVANCED LASER MANUFACTURING TECHNOLOGY}

1015301 Delay time dependence of thermal effect of combined pulse laser machining [10153-8]

1015302 Analysis of the spontaneous Rayleigh-Brillouin scattering spectra of $\mathbf{N}_{2}$ [10153-9]

1015303 Attenuation characteristic of UWB signals propagation in free space [10153-10]

1015304 Algorithm research on infrared imaging target extraction based on GAC model [10153-11]

1015305 Distance measurement to high remote targets based on the airborne chaotic laser [10153-12]

1015306 Laser pulse peak holding circuit for low cost laser tracking applications [10153-13]

1015307 The feature extraction of "cat-eye" targets based on bi-spectrum [10153-15]

1015308 Dual station visualization measuring method of LRCS [10153-16]

1015309 Fast computation of radiation pressure force exerted by multiple laser beams on red blood cell-like particles [10153-17]

10153 OA Photoacoustic signals denoising of the glucose aqueous solutions using an improved wavelet threshold method [10153-18]

$10153 \mathrm{OB}$ Simulation study on thermal effect of long pulse laser interaction with CFRP material [10153-19]

10153 OC Coherence length tunable solid-state lasers based on Fabry-Perot etalon [10153-20]

10153 OD Study of fuzzy adaptive PID controller on thermal frequency stabilizing laser with double longitudinal modes [10153-21]

10153 OE Application research of rail transit safety protection based on laser detection [10153-22]

10153 OF Two dimension interferometric Rayleigh scattering velocimetry [10153-23]

10153 OG Research on the method of precise alignment technology of atmospheric laser communication [10153-24] 
$10153 \mathrm{OH}$ Observation of the Impact of angle of cylinder wedge on wedge waves by laser ultrasound technique [10153-25]

10153 ol Application of lap laser welding technology on stainless steel railway vehicles [10153-26]

10153 0J Detection of cat-eye effect echo based on unit APD [10153-27]

$101530 \mathrm{~K}$ Optical property of few-mode fiber with non-uniform refractive index for cylindrical vector beam generation [10153-29]

$10153 \mathrm{OL}$ Optical system design of subminiature endoscope with imaging fiber bundle [10153-30]

10153 OM Study of laser location based on four-quadrant detector APD [10153-31]

10153 ON Application of drive circuit based on L298N in direct current motor speed control system [10153-32]

1015300 Objective backscattering properties measurements at 2.52 terahertz [10153-33]

10153 OP Controlling software development of $\mathrm{CW}$ terahertz target scattering properties measurements based on LabVIEW [10153-34]

$101530 Q$ Simulation research on 2.52THz radar cross section of conductive column array [10153-35]

10153 OR The optimizations of CGH generation algorithms based on multiple GPUs for 3D dynamic holographic display [10153-36]

10153 OS Hybrid modulation driving power technology for pulsed laser fuze [10153-37]

10153 ОT Design of high-precision ranging system for laser fuze [10153-38]

10153 OU Design of drive circuit of laser diode [10153-40]

$10153 \mathrm{OV}$ Comparative research on the methods for measuring the mode deflection angle of cylindrical resonator gyroscope [10153-41]

10153 oW Laser positioning of four-quadrant detector based on pseudo-random sequence [10153-43]

$101530 \mathrm{X}$ Theoretical analysis of temperature response of the fiber Bragg grating embedded in composite insulator [10153-42]

10153 OY Effect on operating distance of laser rangefinders with deviation between axis of emitting and receiving in turbulent atmosphere [10153-44]

$101530 Z$ Experimental study of 248nm excimer laser etching of alumina [10153-45]

1015310 Transient elastic deformation detection on the metal surface induced by nanosecond laser pulse [10153-46]

1015311 An ultra-narrow-band optical filter based on whispering-gallery-mode hybridmicrosphere-cavity [10153-47] 
1015312 Research on the efficiency of coherent balanced detection [10153-49]

1015313 Dynamic calibration technique for inertial navigation system based on one-dimensional laser Doppler velocimeter [10153-50]

1015314 The design of Gaussian beam zoom system in intermediate and long distance measurement [10153-51]

1015315 Simulation and experiment of near-field nanostructuring on Ti-6AI-4V surface [10153-53]

1015316 Improved pulse laser ranging algorithm based on high speed sampling [10153-52]

1015317 Research on marking lines of silicone elastomer PDMS for super-hydrophobic surface fabrication based on picosecond laser [10153-54]

1015318 A colour image reproduction framework for 3D colour printing [10153-55]

1015319 Laser range profile of cones [10153-56]

$101531 \mathrm{~A}$ High speed sampling circuit design for pulse laser ranging [10153-58] 
Proc. of SPIE Vol. 10153 101531B-6 Downloaded From: https://www.spiedigitallibrary.org/conference-proceedings-of-spie on 26 Apr 2023
Terms of Use: https://www.spiedigitallibrary.org/terms-of-use 


\title{
Authors
}

Numbers in the index correspond to the last two digits of the six-digit citation identifier (CID) article numbering system used in Proceedings of SPIE. The first four digits reflect the volume number. Base 36 numbering is employed for the last two digits and indicates the order of articles within the volume. Numbers start with 00, 01, 02, 03, 04, 05, 06, 07, 08, 09, OA, OB...0Z, followed by 10-1Z, 20-2Z, etc.

\author{
Ai, Yong, 12 \\ Cao, Ercong, OM, OW \\ Cao, Guohuaa, 08 \\ Chen, De-Ying, 0O, OP, OQ \\ Chen, Jian, OG \\ Chen, Qian, OM \\ Chen, Shanshan, OT \\ Chen, Wen, OX \\ Chen, Wen-jian, OG \\ Chen, Yang, 12 \\ Chen, Yong, 06 \\ Chen, Yu-dan, OY \\ Dong, Shiyun, 17 \\ Dong, Xiaopeng, OX \\ Duan, Yuan-yuan, OG \\ Fan, Chang-Kun, 0O, OP \\ Fan, Guihua, 07 \\ Fan, Youchen, 04 \\ Fan, Yuanyuan, $\mathrm{OC}$ \\ Fan, Zhenfang, OV \\ Fang, Xiaodong, $\mathrm{OZ}$ \\ Gang, Xiao, 17 \\ Gao, Chunfeng, 13 \\ Gao, Wei, OG \\ Gao, Xuan-yi, 16, 1A \\ Gong, Lei, 19 \\ Gong, Yanjun, 19 \\ Gou, Ming-Jiang, 09 \\ Gu, Guohua, OM, OW \\ Guo, Hai-chao, 16, 1A \\ Guo, Xiao-kang, 16, 1A \\ Guo, Xing, OM \\ Han, Qingbang, $\mathrm{OH}$ \\ Han, Sen, ON \\ $\mathrm{He}$, Guangzhong, Ol \\ $\mathrm{He}$, Shi-jie, 16, $1 \mathrm{~A}$ \\ $\mathrm{He}$, Xingdao, 02 \\ $\mathrm{He}$, Ying-hong, $\mathrm{OL}$ \\ $\mathrm{Hu}$, Hongtao, $\mathrm{OZ}$ \\ $\mathrm{Hu}$, Wen-Gang, OJ \\ $\mathrm{Hu}$, Xiaobo, OM, OW \\ $\mathrm{Hu}$, Zhi-yun, OF \\ Huang, Jianyu, 10, 15 \\ Huang, Xuegong, OU \\ Huang, Zhonghua, 03 \\ Ji, Fengzhu, 12 \\ Jia, Bing, 08 \\ Jia, Jing, $\mathrm{OH}$ \\ Jin, Guangyong, 01, OB
}

Kou, Renke, 05

Li, Changjun, 18

Li, Hongye, OK

Li, Huan, 16, $1 \mathrm{~A}$

Li, Meng, 03

Li, Qi, 0O, OP, OQ

Li, Qian, 0O, OQ

$\mathrm{Li}$, Ting, OL

Li, Wei, Ol

Li, Xin, OR

$\mathrm{Li}$, Yingchun, 04

Li, Yuchen, ON

Liv, Guodong, OA

Liu, Hongyang, 12

Liu, Jie, OJ

Liu, Juan, OR

Liu, Liguo, OI

Liv, Linqian, 11

Long, Xingwu, 13

Lu, Qingjie, ON

LV, Juan, OL

LV, Qiongyinga, 08

Ma, Jianhui, OX

Ma, Shi-wei, OG

Ma, Xiangfang, OX

$\mathrm{Ma}$, Xiao-long, OL

Ma, Yao, 01, OB

Mo, Qingkai, OD

Pan, Yao, OV

Qian, Rui-hai, 16, 1A

Qian, Weixian, OM, OW

Qian, Xian-mei, OY

Qu, Tianliang, OV

Ran, Yingying, OU

Ren, Zhong, OA

Shao, Jingzhen, $0 Z$

Shao, Jun, OF

Shen, Zhonghua, $\mathrm{OH}$

Sheng, Xin-Qing, 09

Shi, Lin, 10, 15

$\mathrm{Si}$, Jinhai, OF

Sohiab, Ali, 18

Song, Chaoqun, 17

Song, Xingliang, OC

Sun, Bing, OK

Sun, Hao, ON

Sun, Huayan, 07

Sun, Pei-li, 18

Tang, Yanqin, OW 
Tong, Yanqun, 10, 15

Wan, Hongdan, OK, 11

Wang, Bin, 17

Wang, Chunsheng, 01

Wang, Dongya, OV

Wang, Fang, ON

Wang, Haiyan, 05

Wang, Hongxiao, Ol

Wang, Jin, 11

Wang, Kai, OV

Wang, Mengcheng, 14

Wang, Mingjun, 19

Wang, Qi, 13

Wang, Qian, OC

Wang, Quanzhao, ON

Wang, Qun, 13

Wang, Sheng, OF

Wang, $\mathrm{Xi}, \mathrm{OZ}$

Wang, Xiaonan, OX

Wang, Yanqing, 04

Wang, Yanyan, OV

Wang, Yongtian, $O R$

Wang, Zhifei, OE

Wei, Guo, 13

Wu, Dong-Sheng, OJ

Wu, Tao, 02

Wu, Xiaoyi, 10, 15

Wu, Xueming, 05

Wuerger, Sophie, 18

Xia, Ruxiao, 02

Xiao, Kaida, 18

Xiong, Zhihua, OA

$X \cup$, Guangming, OV

$X U, J i, 11$

$X U$, Xiaobin, OS, OT, OU

Xue, Bin, OL

Yan, Shixing, 17

Yan, Xing-tao, OL

Yan, Yining, OD

Yang, Cheng, ON

Yang, Dan, OR

Yang, Fan, OX

Yang, Ming-Lin, 09

Yang, Xiaobo, 12

Yang, Zhe, OY

Yates, Julian M., 18

Yin, Jian-lin, OY

Yin, Liuliu, ON

Ying, Jia-Ju, OJ

Yu, Huan, 02

Yuan, Boshi, 01, OB

Zeng, Xiao, OX

Zhang, Chu, OY

Zhang, $\mathrm{He}, 06$, OS, OT

Zhang, Lin, OK

Zhang, Peng, OJ

Zhang, Tao, OD

Zhang, Tinghua, 07

Zhang, Wei, 01, 06

Zhang, Xiangjin, 06
Zhang, Xina, 08

Zhang, Xinyi, 02

Zhang, Yan-mei, 16, 1A

Zhang, Yingxi, OR

Zhang, Zuxing, OK

Zhao, Xiaodan, 12

Zhao, Yong-Peng, 0O, OP, OQ

Zhou, Bing, OY

Zhou, Jian, 14

Zhou, Wenzhen, 19

Zhou, Yi, OC, 0O, OP

Zhu, Haohan, 11 


\title{
Conference Committees
}

\author{
Conference Chairs \\ Bingheng Lu, Xi'an Jiaotong University (China) \\ Huaming Wang, BeiHang University (China) \\ Lin Li, The University of Manchester (UK) \\ Lan Jiang, Beijing Institute of Technology(China) \\ Yongnian Yan, Tsinghua University (China) \\ Organization Committee
}

Zhongde Shan, China Academy of Machinery Science and Technology (China)

Shuili Gong, National Key Laboratory for Power Beam Processing

Technologies (China)

Wenwu Zhang, Ningbo Institute of Industrial Technology (China)

Program Committee

Shiyun Dong, Academy for Armored Forces Engineering (China)

Ming Li, Xi' an Institute of Optics and Precision Mechanics (China) 
Proc. of SPIE Vol. 10153 101531B-10

Downloaded From: https://www.spiedigitallibrary.org/conference-proceedings-of-spie on 26 Apr 2023 Terms of Use: https://www.spiedigitallibrary.org/terms-of-use 


\section{Introduction}

We had the great honor of organizing the International Symposium on Advanced Laser Manufacturing Technology 2016. It was truly a great pleasure for us to greet the more than 1000 participants from many different countries who attended the symposium. We firmly believe the symposium will become an important international event in the field of optical technology.

The International Symposium on Advanced Laser Manufacturing Technology is sponsored by Chinese Society for Optical Engineering and China High-tech Industrialization Association (CHIA), organized by Chinese Society for Optical Engineering (CSOE), Photoelectronic Technology Committee, Chinese Society of Astronautics, Photo-electronic Industrialization Committee, CHIA, Department of Cooperation and Coordination for Industry, Academe and Research, CHIA.

The purpose of the symposium is to provide a forum for the participants to report and review innovative ideas and up-to-date progress and developments, and discuss novel approaches to application in the optical field. It is sincerely hoped that the research and development in optical field will be promoted, and the international cooperation sharing the common interest be enhanced.

On behalf of the other co-chairmen, and the Organization Committee of the conference, we would like to heartily thank our sponsors and cooperating organizers for all they have done for the symposium. Thanks also to all the authors for their contributions to the proceedings, to all of the participants and friends for their interest and efforts in helping us to make the symposium possible, to the Program Committee for their effective work and valuable advice, especially the Secretariat, and to the SPIE staff for their tireless efforts and outstanding service in preparing the symposiums and publishing the proceedings.

\section{Bingheng Lu Huaming Wang}


Proc. of SPIE Vol. 10153 101531B-12

Downloaded From: https://www.spiedigitallibrary.org/conference-proceedings-of-spie on 26 Apr 2023 Terms of Use: https://www.spiedigitallibrary.org/terms-of-use 